\title{
Using an aggregate production simulation model with ecological interactions to explore effects of fishing and climate on a fish community
}

\author{
Robert J. Gamble*, Jason S. Link \\ National Marine Fisheries Service, Northeast Fisheries Science Center, 166 Water Street, Woods Hole, Massachusetts 02543, USA
}

\begin{abstract}
Ecosystem-based fishery management requires operating models that are capable of evaluating the effects of a triad of drivers (exploitation, ecological interactions, and the physical environment) on fish populations. We present a simple operating model, AGG-PROD, that takes into account these drivers. AGG-PROD aggregates species into functional groups and applies exploitation rates to these groups, while accounting for the interactions between these groups and the environment. We loosely modeled the Northeast US Large Marine Ecosystem fish community, exploring a range of harvest, ecological interactions (competition and predation), and climate effects scenarios. We examined the independent effects of each of the triad of drivers at their base levels on the 3 main functional groups. We then explored the effects of targeted harvest on specific functional groups as well as different levels of total system harvest, both with and without climate effects. Our results indicate that the triad of drivers can lead to unanticipated, indirect effects on groups of species, and that all 3 should be taken into account by an operating model in a Management Strategy Evaluation context. Harvest tends to affect groups with a slower overall growth rate the most, while groups affected by strong ecological interactions often exhibit strong competitive or predatory release when other groups are reduced in biomass. Climate effects reduce primarily the biomass of groundfishes in our model, indicating the need for more conservative exploitation under future climate projections.
\end{abstract}

KEY WORDS: Ecosystem-based fishery management $\cdot$ Production model $\cdot$ Ecological interactions Climate $\cdot$ Exploitation - Northeast United States Large Marine Ecosystem $\cdot$ Management strategy evaluation · Triad of drivers

Resale or republication not permitted without written consent of the publisher-

\section{INTRODUCTION}

Ecosystem-based fisheries management (EBFM) has called for broader consideration of the factors which impact on the dynamics of living marine resources (LMR) (NMFS 1999, Link 2002a,b, 2010, Pikitch et al. 2004). One of the common themes in these calls for EBFM is the need to consider a triad of drivers (see Fig. 1 in Link et al. 2012, this Theme Section) that influence fish populations: (1) fisheries exploitation, (2) physico-chemical factors (especially climate), and (3) ecological interactions among species (Link et al. 2010a). Fisheries exploitation is long understood to have direct effects on marine ecosystems through direct removals of exploited stocks (Pauly \& Christensen 1995, Worm et al. 2009), and inducing indirect effects on other species in the ecosystem via predatory (Sissenwine 1984, Bax 1991, 1998, Christensen 1996, Link 2002a) or competitive release (Link 2002a). Overfishing also leads to ecosystem level effects such as eutrophication, outbreaks of disease in the trophic levels beneath the overfished species, and species introductions (Jackson et al. 2001). Ecological interactions and related trophodynamic processes, such as predation or competition as referred to above, are also recognized as potentially 
dominant drivers (Frank et al. 2005, Daskalov et al. 2007, Tyrrell et al. 2011). Physico-chemical drivers are important in that fisheries production is linked to primary production (Ware \& Thomson 2005, Chassot et al. 2010), early life history survivorship is at least partially, if not mainly, dictated by biophysical conditions (Beaugrand et al. 2003, Platt et al. 2003), and climate change can affect marine populations (Anderson \& Piatt 1999, Chavez et al. 2003, Nye et al. 2009). While each of these drivers can have important effects on an ecosystem, they are not routinely considered simultaneously (cf. Lucey \& Nye 2010, Fulton et al. 2011). Thus there is a need for models that can explicitly explore the effects of this triad of drivers on an ecosystem simultaneously.

Another key element of EBFM is to determine the maximum sustainable yield (MSY) in an ecosystem (Link 2010). Doing so is important, as each ecosystem has known limitations to productivity (Pauly \& Christensen 1995), with the amount of fish harvested ultimately limited by primary production (Ryther 1969, Ware \& Thomson 2005). There are methods of estimating MSY for an ecosystem. These methods effectively account for a broader set of consideration (e.g. species interactions, climate) than methods for calculating single species MSY, and thus can give quite different results than a simple summation of all species production for a given ecosystem (Au 1973, May 1975, Pope 1975, 1979, Brown et al. 1976, Fukuda 1976, May et al. 1979, Walters et al. 2005, NEFSC 2008, Tyrrell et al. 2011).

The combination of, and interactions between, these drivers suggests the need to utilize a Management Strategy Evaluation (MSE; Smith et al. 1999, Sainsbury et al. 2000). MSEs have a core operating model capable of evaluating this triad of drivers under a variety of scenarios. Executing such an MSE should take the relative effects of these drivers into consideration and be able to provide outputs related to achieving a system-level MSY, as well as exploring tradeoffs among the species and drivers inherent to an ecosystem.

While there are many classes of extant ecosystem models that could serve as MSE operating models, there is an important class of models between the simpler, stock-focused models that are typical in stock assessments (or that incorporate other factors such as Extended Single-species Assessment Models, ESAMs) and the full ecosystem models such as GADGET, APECOSM, InVitro, or ATLANTIS. Aggregate Surplus Production (ASP) models are part of this intermediate class of models (Hollowed et al. 2000, Plagányi 2007, Townsend et al. 2008, Link et al. 2010b). These models require the same basic inputs as standard stock assessment models or ESAMs, but are aggregated across species at a higher level of biological hierarchy. ASPs estimate biological reference points (BRPs) commonly used in LMR management (such as MSY), but for an aggregate group of species. ASP models can also simulate the effects of ecological interactions, harvest, and climate, making them a valuable tool generally for EBFM and specifically within an MSE context as an operating model (Link et al. 2010c).

Such ASP models have a number of advantages. They fall into the simpler range of the complexity continuum of models. Models of low to intermediate complexity often have higher forecast skill than more complex models (Costanza \& Sklar 1985, Walters 1986, Fulton et al. 2003, Adkison 2009, Hannah et al. 2010). Additionally, surplus production models can outperform age-structured models in providing more robust characterizations of fish population dynamics (Ludwig \& Walters 1985, 1989, Hilborn \& Walters 1992). For instance, Ludwig \& Walters (1985) generated data from a model with 2 age classes (prerecruitment and catchable adults) with random recruitment (Deriso 1980). When they fit parameters from both the original age-structured model and a simple surplus production model to the generated data, the surplus production model performed just as well or better than the original model. Additionally, ASPs rely on relatively common and easy to collect data (biomass or abundance estimates and fisheries landings) and thus are of use even in many data-limited ecosystems (Graham 1935, Pitcher \& Hart 1982, Smith 1994). ASP models can incorporate stochasticity, trophic interactions, and environmental and climate forcing relatively simply and easily (Clark et al. 2003, Rose 2004, Jacobson et al. 2005, Keyl \& Wolff 2008). ASP models capitalize on the stability of aggregate groupings that, although dynamic, are nevertheless less variable than those commonly observed for their component species (Duplisea \& Blanchard 2005, Auster \& Link 2009). Finally, ASPs produce outputs that are widely used in fisheries management and do not require additional familiarization for managers.

Although several assumptions need to be met for use of ASP models (e.g. comparable life histories and vital rates among species within an aggregate group), these models have the ability to provide synthetic information useful for implementing EBFM. The main strengths of this approach are its relative simplicity, minimal assumptions, requirement of readily available data, and relative portability of the approach for ease of use on different data sets. The 
drawbacks are those usually associated with production models (e.g. missing internal stage or age related dynamics, and ignoring different life history characteristics of individual species within an aggregation, which is explored more thoroughly in Gaichas et al. 2012, this Theme Section).

Here we describe a particular ASP model, AGGPROD, which is an aggregated application of MSPROD (Gamble \& Link 2009) used to model functional groups of species. The objectives in doing so are to explore the aggregate properties and outputs from modeling such groups, and contrast various scenarios that could be used in an MSE context among the triad of drivers that influence LMR dynamics. Our focus here is to explore how aggregate BRPs change under differing scenarios.

\section{METHODS}

\section{Model description}

We used an application of AGG-PROD to examine the effects of different harvest, climate, and ecological scenarios on aggregated groups of fish loosely parameterized to reflect the Northeast US Large Marine Ecosystem (NEUS LME). This model is a variation of an MS-PROD, a multi-species surplus production model described previously (Gamble \& Link 2009), where instead of individual species, aggregated, functional groups were considered. AGGPROD is identical to MS-PROD, except that due to lack of a species focus, the within-group competition terms are removed. The model formulation is:

$$
\frac{\mathrm{d} B_{I}}{\mathrm{~d} t}=r_{I} B_{I}\left(1-\frac{B_{I}}{K_{I}}-\frac{\sum_{1}^{G} \beta_{I G} B_{G}}{\left(K_{\sigma}-K_{G}\right)}\right)-B_{I} \sum_{1}^{P} \alpha_{I P} B_{P}-h_{I} B_{I}
$$

where $B_{I}$ is the biomass of an aggregated group of species or stocks $(I), r_{I}$ is the growth rate of group $I, K_{I}$ is the carrying capacity of group $I_{I} h_{I}$ is the harvest rate (a proxy for fishing mortality, defined as the instantaneous removal rate) on group $I, G$ is a group other than $I$ with corresponding $B$ and $K, \beta_{I G}$ is the competition interaction coefficient between groups $I$ and $G, K_{\sigma}$ is the system carrying capacity, $P$ is a group which preys on group $I$ with a corresponding $B$, and $\alpha_{I P}$ is the predation interaction coefficient between groups $I$ and $P$.

This model framework is based on the general form of extended Schaefer-types of models (e.g. Prager 1994, Collie \& DeLong 1999. Mueter \& Megrey 2006,
Gamble \& Link 2009) and has been employed for all fished species in over 10 northern hemisphere ecosystems (Bundy et al. 2012, this Theme Section, Lucey et al. 2012, Theme Section). This resultant form here is similar to other fisheries production models applied in the NEUS region (e.g. Spencer \& Collie 1996, Collie \& DeLong 1999) and elsewhere (e.g. Constable 2001, Mueter \& Megrey 2006). Unlike those other approaches, here we are aiming to simulate a system with specified parameters, not fit it to the typical data series, in an MSE context. The other distinction of our approach is that, like Lucey et al. (2012), the main aspects that influence aggregate dynamics are partitioned into their explicit ecological and fishing factors. We also note that values of $K$ are fixed and not linked to prey population abundances. Although the latter would be feasible, for this approach we simply address the relative impacts of harvesting, predation, and competition rather than the feedback among predator-prey linkages. We address climate effects via alterations to $r$ (see 'Scenarios' below).

We note the following major assumptions of our modeling approach:

(1) Aggregated groups have a carrying capacity that is distinct from the systemic carrying capacity, but such a systemic carrying capacity does exist (e.g. Brown et al. 1976, May et al. 1979, Pauly \& Christensen 1995, Pauly et al. 1998, 2002).

(2) Harvest and species interactions (competition and predation) in our model may similarly influence a group's ability to reach its carrying capacity (e.g. May 1975, Pope 1975, 1979, Brown et al. 1976, Fukuda 1976).

(3) Considering only aggregated groups will not reveal whether aggregated fishing mortality levels might cause specific stocks within the group to be overfished, or indeed what the likely result of any set of fishing levels will be on individual stocks (Worm et al. 2009, Gaichas et al. 2012).

(4) There is no age structure in the model, and therefore the effects of stage-specific mortality, growth, and related demographic processes cannot be modeled.

\section{Base model parameterization and simulations}

The parameterization for the simulations using AGG-PROD was informed by the parameterization for MS-PROD, which was applied to a simulated fish community that was generally based on the NEUS LME (Gamble \& Link 2009). We parameterized the model for 3 groups: groundfishes, small pelagics, and 
elasmobranchs. We chose these groupings primarily because they correspond to the fishery management plans in the region. While groundfishes could have been further split into gadids, flatfish, and an 'other' groundfish group, we considered the groups chosen to have enough similarity among life history parameters used in the model. Specifically, the species chosen for the groundfish group have growth rates higher than those in the elasmobranch group, and lower than those in the small pelagics group. Additionally, competition (for space and due to diet overlap) is likely greater for the members of the groundfish group than for members of the elasmobranch or small pelagics groups.

The biomasses for each group were calculated by summing the individual biomasses for each stock within the group (NEFSC 2002, 2007, Overholtz et al. 2008). While each stock was not considered individually, the component stocks present in each group are shown in Table 1. Growth rates $(r)$ for each group were calculated based on a biomass-weighted average of the individual $r$ values from the MS-PROD formulation. The individual $r$ values were calculated by doubling estimates of fishing mortality at maxi-

Table 1. List of stocks within each group in this formulation of AGG-PROD. CC: Cape Cod, GOM: Gulf of Maine, GB: Georges Bank, SNE: Southern New England, MAB: MidAtlantic Bight

\begin{tabular}{|c|c|}
\hline Group & Stocks \\
\hline Groundfishes & $\begin{array}{l}\text { American plaice } \\
\text { CC-GOM yellowtail } \\
\text { GB yellowtail } \\
\text { GB cod } \\
\text { GB haddock } \\
\text { GB winter flounder } \\
\text { GOM-GB windowpane } \\
\text { GOM cod } \\
\text { GOM haddock } \\
\text { Halibut } \\
\text { Ocean pout } \\
\text { Pollock } \\
\text { Redfish } \\
\text { SNE-MAB windowpane } \\
\text { SNE-MAB winter flounder } \\
\text { SNE-MAB yellowtail } \\
\text { White hake } \\
\text { Witch flounder }\end{array}$ \\
\hline Small pelagics & $\begin{array}{l}\text { Butterfish } \\
\text { Herring } \\
\text { Mackerel }\end{array}$ \\
\hline Elasmobranchs & $\begin{array}{l}\text { Skates } \\
\text { Spiny dogfish }\end{array}$ \\
\hline
\end{tabular}

mum sustainable yield ( $\left.F_{\mathrm{MSY}}\right)$ for groundfishes, pelagics, and elasmobranchs (Applegate et al. 1998, Quinn \& Deriso 1999, Hilborn \& Walters 1992, NEFSC 2002, 2007, Overholtz et al. 2008). System fish carrying capacity $(K)$ was set to $\sim 700000 \mathrm{mt}$ as the sum of the group $K$ values for groundfishes $(\sim 2800000 \mathrm{mt})$, small pelagics ( 2600000 mt), and elasmobranchs ( 2300000 mt). These $K$ values were estimated as twice $B_{\mathrm{MSY}}$ for individual stocks within each group and then summed (by definition; Applegate et al. 1998, Quinn \& Deriso 1999, Hilborn \& Walters 1992, NEFSC 2002, 2007, Overholtz et al. 2008). Competition coefficients between groups were informed by diet matrices and overlap in habitat. Predation was set only on the pelagics, as informed by stomach content data (Link \& Almeida 2000). Spatial overlap was set to 0.6 between all groups based largely upon information of seasonal movements for the pelagic and elasmobranch species derived from fishery independent surveys. These salient parameters used to initialize the base model are given in Table 2 .

Fisheries removals (i.e. harvest, $h$ ) were set as an annual rate of removal for each group. We set these in accordance to the scenarios we ran (see 'Scenarios' below).

We ran the simulations for $30 \mathrm{yr}$ with an annual time step. The model was developed in Visual C++

Table 2. Basic parameterization for the AGG-PROD simulation model. $B_{\mathrm{MSY}}$ : biomass at maximum sustainable yield

\begin{tabular}{|lccc|}
\hline Parameter & $\begin{array}{c}\text { Ground- } \\
\text { fishes }\end{array}$ & $\begin{array}{c}\text { Elasmo- } \\
\text { branchs }\end{array}$ & Pelagics \\
\hline Growth rate & 0.45 & 0.2 & 0.6 \\
Initial biomass (mt) & 834002 & 756418 & 3377800 \\
Carrying capacity (mt) & 2849576 & 2311462 & 2591956 \\
$B_{\text {Msy (m) }}$ & 1424788 & 1155731 & 1295978 \\
Competition coefficient no. 1 & & & \\
Between Group and Groundfishes & 0 & 0.5 & 0 \\
Between Group and Elasmo- & 1 & 0 & 0.05 \\
$\quad$ branchs & & & \\
Between Group and Pelagics & 0 & 0.1 & 0 \\
Predatory loss rates & & & \\
With Groundfishes & 0 & 0 & $8.00 \times 10^{-8}$ \\
With Elasmobranchs & 0 & 0 & $2.00 \times 10^{-7}$ \\
With Pelagics & 0 & 0 & 0 \\
Spatial overlap & & & \\
With Groundfishes & 0.6 & 0.6 & 0.6 \\
With Elasmobranchs & 0.6 & 0.6 & 0.6 \\
With Pelagics & 0.6 & 0.6 & 0.6 \\
Harvest loss rate & 0.1 & 0.1 & 0.1 \\
Demersal & 1 & 1 & 0 \\
Pelagic & 0 & 0 & 1 \\
\hline
\end{tabular}


and utilizes a calculation engine designed to account for multiple iterations of simultaneous equation (i.e. groups) solving, using a fourth-order Runge-Kutta numerical integration algorithm. (Note: we developed a software package which utilizes a graphical user interface to handle data inputs for model initialization, parameterization, and scenario development, and additionally to handle and process model outputs. This package is available from the authors upon request.) The current version of the model is a simulator that produces deterministic results, with no direct data fitting beyond the data used to inform the initial parameterization.

\section{Scenarios}

We ran 3 classes of scenarios to explore the effects of the triad of drivers on aggregate groups (Table 3). Each class of scenarios was run with 2 different sets of parameters for the groundfish group. The first parameter set used the base parameters described previously. The second parameter set decreased the groundfishes growth rate by $10 \%(r=0.405)$ to simulate a negative effect on growth due to climate change. Previous work has linked changes in the intrinsic rate of growth or carrying capacity to climate changes (Brander 1995, O'Brien et al. 2000, Attrill \& Power 2002, Clark et al. 2003, Gislason et al. 2010). We applied this climate effect on growth rate only to groundfishes. This was due to small pelagics (e.g. Atlantic herring, Atlantic mackerel, and butterfish) having generally larger range distributions, and hence wider optimal thermal regimes, than groundfishes. Additionally, a recent study (Nye et al. 2009) indicated that many individual stocks of groundfishes in the NEUS LME showed a recent range contraction due to climate effects, while pelagic stocks and all but 1 elasmobranch showed range expansions or no change. Specifically, of the 19 species that make up the aggregate groundfish group, 8 showed a northward movement and 2 showed a southward movement (Nye et al. 2009). Additionally, 8 species showed a range contraction and 2 showed a range expansion. These range changes, especially contractions and poleward movements, are indicative of probable accommodation of differential growth rates relative to changing ambient water temperatures, as approximated here by the change in $r$. The toggling of the climate effect on groundfish growth rates are seen in Table 3 as the 'Climate effects' column, either with base growth parameters $(\mathrm{N})$ or the modified parameter for groundfishes $(\mathrm{Y})$.
Table 3. Settings for each of the 3 scenario classes exploring the effects of the triad of drivers on aggregate groups. (A) Combination scenarios. The 3 drivers were each toggled on and off at a base level to determine the relative effects of each. Harvest rate $(h)$ : ' $\mathrm{Y}$ ' means $h$ set at 0.1 ; 'N' means $h$ set at 0.0. Ecological interactions: ' $Y$ ' means competition and predation were set as parametized in Table $2 ;$ ' $N$ ' means all competition and predation were set to zero. Climate effects: ' $\mathrm{Y}$ ' means groundfish growth rate $(r)$ set at 0.405 to simulate climate effects on growth; ' $\mathrm{N}$ ' means groundfish $r$ set to base value of 0.45 (as per Table 2). (B) Target harvest scenarios. Harvested group: $h$ set at 0.3 for this group, the rest set at $h=0$. Ecological interactions: always ' $\mathrm{Y}$ ' as defined in (A). Climate effects: ' $\mathrm{Y}^{\prime}=$ on, ' $\mathrm{N}$ ' = off, as defined in A. (C) System harvest scenarios. Harvest rate: $h$ set to a specific value. Ecological interactions: always ' $\mathrm{Y}$ ' as defined in (A). Climate effects: ' $\mathrm{Y}$ ' = on, ' $\mathrm{N}$ ' = off, as defined in (A)

\begin{tabular}{|c|c|c|c|}
\hline \multicolumn{4}{|c|}{ (A) Combination scenarios } \\
\hline Scenario & $\begin{array}{l}\text { Harvest } \\
\text { rate }\end{array}$ & $\begin{array}{c}\text { Ecological } \\
\text { interactions }\end{array}$ & $\begin{array}{c}\text { Climate } \\
\text { effects }\end{array}$ \\
\hline 1 & $\mathrm{~N}$ & $\mathrm{~N}$ & $\mathrm{~N}$ \\
\hline 2 & $\mathrm{Y}$ & $\mathrm{N}$ & $\mathrm{N}$ \\
\hline 3 & $\mathrm{~N}$ & $\mathrm{Y}$ & $\mathrm{N}$ \\
\hline 4 & $\mathrm{Y}$ & $\mathrm{Y}$ & $\mathrm{N}$ \\
\hline 5 & $\mathrm{~N}$ & $\mathrm{~N}$ & $\mathrm{Y}$ \\
\hline 6 & $\mathrm{Y}$ & $\mathrm{N}$ & $\mathrm{Y}$ \\
\hline 7 & $\mathrm{~N}$ & $\mathrm{Y}$ & $\mathrm{Y}$ \\
\hline 8 & $\mathrm{Y}$ & $\mathrm{Y}$ & $\mathrm{Y}$ \\
\hline \multicolumn{4}{|c|}{ (B) Targeted harvest scenarios } \\
\hline Scenario & $\begin{array}{c}\text { Harvested } \\
\text { group }(h=0.3)\end{array}$ & $\begin{array}{l}\text { Ecological } \\
\text { interactions }\end{array}$ & $\begin{array}{l}\text { Climate } \\
\text { effects }\end{array}$ \\
\hline 1 & Groundfishes & $\mathrm{Y}$ & $\mathrm{N}$ \\
\hline 2 & Elasmobranchs & $\mathrm{Y}$ & $\mathrm{N}$ \\
\hline 3 & Pelagics & $\mathrm{Y}$ & $\mathrm{N}$ \\
\hline 4 & Groundfishes & $\mathrm{Y}$ & $\mathrm{Y}$ \\
\hline 5 & Elasmobranchs & $\mathrm{Y}$ & $\mathrm{Y}$ \\
\hline 6 & Pelagics & $\mathrm{Y}$ & $\mathrm{Y}$ \\
\hline \multicolumn{4}{|c|}{ (C) System harvest scenarios } \\
\hline Scenario & $\begin{array}{l}\text { Harvest } \\
\text { rate }\end{array}$ & $\begin{array}{l}\text { Ecological } \\
\text { interactions }\end{array}$ & $\begin{array}{l}\text { Climate } \\
\text { effects }\end{array}$ \\
\hline 1 & 0 & $\mathrm{Y}$ & $\mathrm{N}$ \\
\hline 2 & 0.01 & $\mathrm{Y}$ & $\mathrm{N}$ \\
\hline 3 & 0.05 & $\mathrm{Y}$ & $\mathrm{N}$ \\
\hline 4 & 0.1 & $\mathrm{Y}$ & $\mathrm{N}$ \\
\hline 5 & 0.2 & $\mathrm{Y}$ & $\mathrm{N}$ \\
\hline 6 & 0.3 & $\mathrm{Y}$ & $\mathrm{N}$ \\
\hline 7 & 0.5 & $\mathrm{Y}$ & $\mathrm{N}$ \\
\hline 8 & 0 & $\mathrm{Y}$ & $\mathrm{Y}$ \\
\hline 9 & 0.01 & $\mathrm{Y}$ & $\mathrm{Y}$ \\
\hline 10 & 0.05 & $\mathrm{Y}$ & $\mathrm{Y}$ \\
\hline 11 & 0.1 & $\mathrm{Y}$ & $\mathrm{Y}$ \\
\hline 12 & 0.2 & $\mathrm{Y}$ & $\mathrm{Y}$ \\
\hline 13 & 0.3 & $\mathrm{Y}$ & $\mathrm{Y}$ \\
\hline 14 & 0.5 & $\mathrm{Y}$ & $\mathrm{Y}$ \\
\hline
\end{tabular}


The first class of scenarios, the combination scenarios, independently toggled ecological interactions (competition between all groups, and predation on small pelagics), harvest, and climate effects. Ecological interactions were toggled off by removing interaction terms. Harvest scenarios were toggled on $(h=$ $0.1)$ or off $(h=0)$. Climate effects were toggled on $(r=$ 0.405 for groundfishes) or off ( $r=0.45$ for groundfishes) for each scenario in this class.

The second class of scenarios, the targeted harvest scenarios, examined targeted harvest rates on a specific group both with ( $r=0.405$ for groundfishes) and without ( $r=0.45$ for groundfishes) climate effects. One of the groups was subjected to a higher harvest rate $(h=0.3)$ while the other 2 were subjected to a base harvest rate $(h=0.1)$.

The third set of scenarios, the system harvest scenarios, examined the effects of increasing harvest rates on the entire system, again with climate effects toggled on ( $r=0.405$ for groundfishes) or off ( $r=0.45$ for groundfishes). All groups simultaneously had their harvest rates set to: $0,0.01,0.05,0.1,0.2,0.3$, and 0.5 .

In all scenarios, it was possible to partition the losses to biomass to each group at each time step for each type of removal (predation, competition, and harvest). The MS-PROD software package, using the Runge-Kutta numerical integration algorithm calculates these removals at each step of the algorithm and they can then be summed to provide the final removal at each time step of the model. Losses or increases due to climate were calculated as the difference between a group's biomass in a scenario which did not include climate effects, and the corresponding non-climate version of a scenario.

\section{RESULTS}

In all scenarios, we expressed the results both in terms of biomass (mt) and as a proportion of group $B_{\mathrm{MSY}}$ such that a value greater than 1.0 indicated the group was higher than its $B_{\mathrm{MSY}}$, and a value less than 1.0 indicated the group did not reach the group $B_{\mathrm{MSY}}$.

\section{Combination scenarios}

For the combination class of scenarios (where we toggled ecological interactions, harvest, and climate effects separately) the main results show some common patterns. In Scenario 1 (interactions off, $h=0$, groundfish $r=0.45$ ), all groups asymptotically approach their carrying capacities (Fig. 1a). Because of this, each group's final biomass is almost equal to its carrying capacity, and therefore almost double the group's $B_{\mathrm{MSY}}$ (Table 4 ).

In Scenario 2 (interactions off, $h=0.1$, groundfish $r=0.45$ ), no groups reached their carrying capacities (Fig. 1b). Elasmobranchs showed a final biomass less than half that in Scenario 1. The other 2 groups also showed a drop in final biomass, but not to the same extent. Only elasmobranchs fell below a $B_{\text {final }} / B_{\mathrm{MSY}}$ ratio of 1.0 in this scenario (Table 4 ).

In Scenario 3 (interactions on, $h=0$, groundfish $r=$ 0.45), no groups reached their carrying capacity. Small pelagics showed a final biomass of less than half that in Scenario 1. Elasmobranchs had a higher biomass, and groundfishes had a lower biomass than in Scenario 2 (Fig. 1c), indicating that harvest effects are stronger than interaction effects on elasmobranchs in the simulated ecosystem while interaction effects are likely stronger than harvest effects on groundfish. Additionally, in this scenario there was a switch in ecosystem dominance (in terms of final biomass) between elasmobranchs and groundfishes (compared to the groundfish-dominated Scenarios 1, 2 , and 4) Only small pelagics fell below a $B_{\text {final }} / B_{\mathrm{MSY}}$ ratio of 1.0 in this scenario (Table 4 ).

In Scenario 4 (interactions on, $h=0.1$, groundfish $r=$ 0.45), no groups reached their carrying capacity. Elasmobranchs showed a final biomass more than twothirds less than in Scenario 1, while the other 2 groups had a final biomass at or slightly more than in Scenario 3 due to release of groundfishes and pelagics by elasmobranchs (Fig. 1d). Again, only elasmobranchs fell below a $B_{\text {final }} / B_{\mathrm{MSY}}$ ratio of 1.0 in this scenario (Table 4 ).

Scenarios 5 to 8 are equivalent to Scenarios 1 to 4 , but with climate effects turned on (groundfish $r=$ 0.405). In Scenario 5 (interactions off, $h=0$, groundfish $r=0.405$ ), it took longer for the groundfish group to reach its carrying capacity compared to Scenario 1 (same but with groundfish $r=0.45$ ) due to climate being modeled as a reduction in growth rate. In Scenario 6 (interactions off, $h=0.1$, groundfish $r=0.405$ ), the groundfish group had a $3.2 \%$ lower biomass and a correspondingly lower $B_{\text {final }} / B_{\mathrm{MSY}}$ ratio when compared to Scenario 2 (same but with groundfish $r=$ $0.45)$, while the other 2 groups were largely unaffected. In Scenario 7 (interactions on, $h=0.0$, groundfish $r=0.405)$, the $B_{\text {final }} / B_{\mathrm{MSY}}$ ratios for all groups were the same as in Scenario 3 (same but with groundfish $r=0.45$ ). In Scenario 8 (interactions on, $h=0.1$, groundfish $r=0.405$ ), the groundfish group had a $4.5 \%$ lower biomass and a correspondingly lower $B_{\text {final }} / B_{\mathrm{MSY}}$ ratio when compared to Scenario 4 (same but with groundfish $r=0.45$ ) (Table 4). 


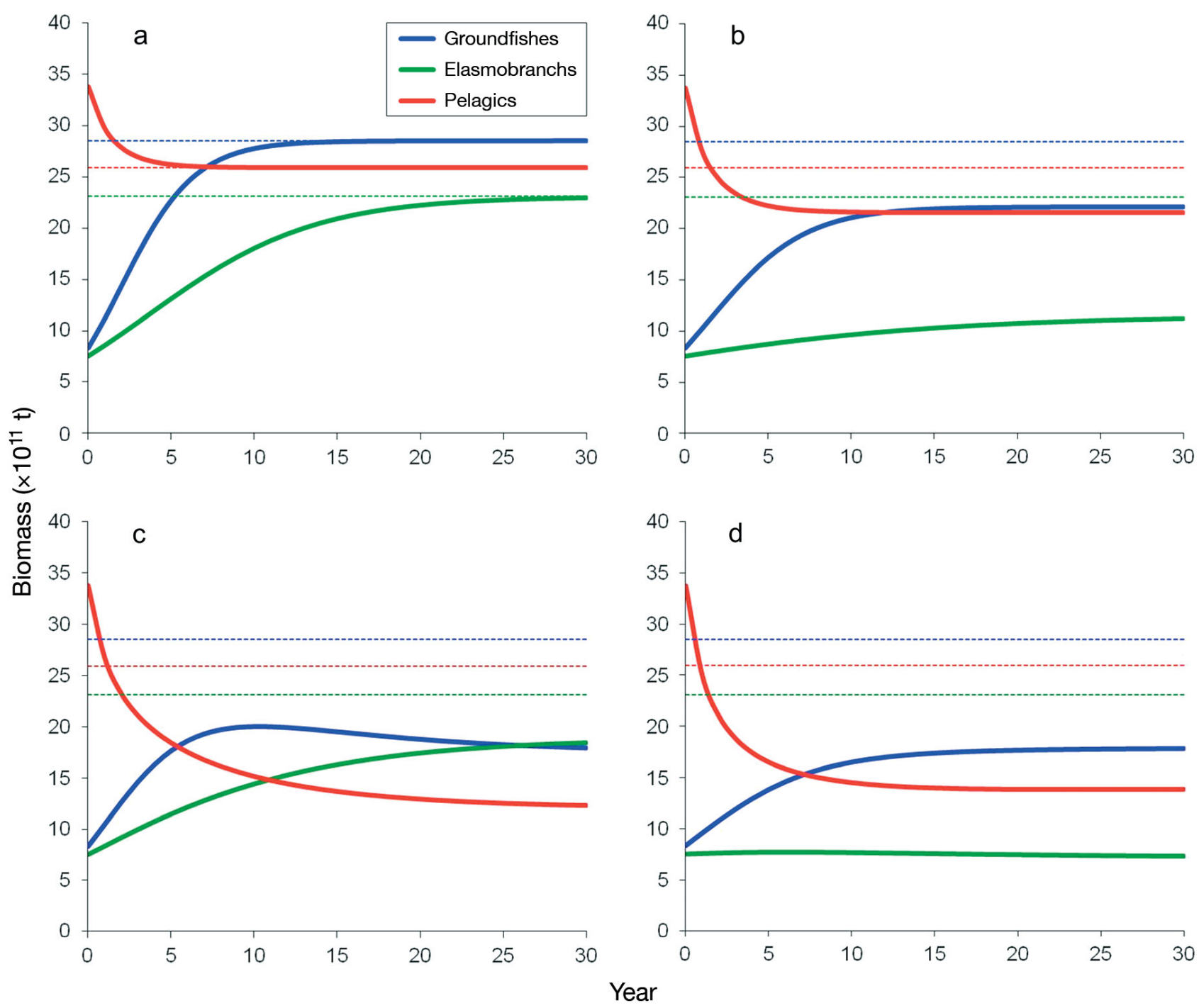

Fig. 1. Results from the combination class of scenarios, showing the effects of independently toggling harvest and interactions: (a) no harvest and no interactions, (b) harvest and no interactions, (c) no harvest but interactions present, (d) harvest and interactions. The dotted lines represent the carrying capacities of each group

Table 4. Summary of combination scenarios of final biomass to biomass at maximum sustainable yield $\left(B_{\text {final }} / B_{\mathrm{MSY}}\right)$ ratios. In the Harvest, Interactions, and Climate columns, a ' $\mathrm{Y}$ ' indicates that the corresponding effect on the system is turned on, and a ' $N$ ' indicates that the corresponding effect on the system is turned off (see Table 3 for definitions). Bold values are $<1$, indicating that this group did not reach the group $B_{\mathrm{MSY}}$

\begin{tabular}{|c|c|c|c|c|c|c|c|}
\hline \multirow{2}{*}{ Scenario } & \multirow{2}{*}{ Harvest } & \multirow{2}{*}{ Interactions } & \multirow{2}{*}{ Climate } & \multicolumn{4}{|c|}{ Combination $B_{\text {final }} / B_{\mathrm{MSY}}$} \\
\hline & & & & Groundfishes & Elasmobranchs & Small pelagics & System \\
\hline 1 & $\mathrm{~N}$ & $\mathrm{~N}$ & $\mathrm{~N}$ & 2.00 & 1.99 & 2.00 & 2.00 \\
\hline 2 & $\mathrm{Y}$ & $\mathrm{N}$ & $\mathrm{N}$ & 1.56 & 0.97 & 1.67 & 1.42 \\
\hline 3 & $\mathrm{~N}$ & $\mathrm{Y}$ & $\mathrm{N}$ & 1.26 & 1.60 & 0.95 & 1.26 \\
\hline 4 & $\mathrm{Y}$ & $\mathrm{Y}$ & $\mathrm{N}$ & 1.25 & 0.64 & 1.07 & 1.01 \\
\hline 5 & $\mathrm{~N}$ & $\mathrm{~N}$ & $\mathrm{Y}$ & 2.00 & 1.99 & 2.00 & 2.00 \\
\hline 6 & $\mathrm{Y}$ & $\mathrm{N}$ & $\mathrm{Y}$ & 1.51 & 0.97 & 1.67 & 1.40 \\
\hline 7 & $\mathrm{~N}$ & $\mathrm{Y}$ & $\mathrm{Y}$ & 1.26 & 1.60 & 0.95 & 1.26 \\
\hline 8 & $\mathrm{Y}$ & $\mathrm{Y}$ & $\mathrm{Y}$ & 1.20 & 0.65 & 1.08 & 0.99 \\
\hline
\end{tabular}


Generally, the elasmobranch and pelagic groups showed minimal changes in final biomass in the scenarios where climate effects were present (Scenarios 5-8) compared to the non-climate scenarios (Scenarios 1-4). Furthermore, adding the climate effects did not have an impact on final biomasses and therefore the $B_{\text {final }} / B_{\text {MSY }}$ ratio of the groundfish group unless harvest was also occurring. Finally, in all of the combination scenarios except Scenario 8 (interactions on, $h=0.1$, groundfish $r=0.405)$, the total system $B_{\text {final }} / B_{\text {MSY }}$ ratio remained above 1.0 , although only barely so in the case of Scenario 4 (interactions on, $h=0$, groundfish $r=0.405)$. In the case of Scenario 8, the total system $B_{\text {final }} / B_{\text {MSY }}$ ratio was 0.99 (Table 4 ).

The comparative effects of species interactions, climate, and harvest differ among the 3 groups (Fig. 2). When all 3 are present in Scenario 8 (interactions on, $h=0.1$, groundfish $r=0.405)$, groundfishes are affected strongly by harvest, which, in the last year of the run, is responsible for $48 \%$ of the removals of biomass. Of the losses, $30 \%$ come from competition with the other guilds, and $22 \%$ come from the effects of climate (Fig. 2a). Elasmobranchs are most strongly affected by harvest, which is responsible for $73 \%$ of losses to biomass in the final year of the run, while competition is responsible for $27 \%$ (Fig. 2b). Pelagics are the most affected by species interactions of the 3 groups (Fig. 2c), and in the final year of the run most of the losses (62\%) come from predation, $36 \%$ of the losses come from harvest, and the remaining $2 \%$ come from competition.

\section{Targeted harvest scenarios}

In the targeted harvest class of scenarios, where interactions were turned on, the harvest rate was set to 0.1 for 2 groups while the third was set to 0.3 , and climate effects were toggled off (groundfish $r=0.45$ ), there were 4 main results.

(1) Not surprisingly, the final biomass for each group was lowest when it was assigned the higher harvest rate. This sometimes resulted in shifts in ecosystem structure when compared to the combination scenarios. For example, when combination Scenario 4 (interactions on, $h=0.1$, groundfish $r=0.45$ ) was compared to the targeted harvest Scenarios 1 to 3 , shifts in pelagic versus demersal dominance of the modeled ecosystem were seen (Fig. 3a-d). Also, in targeted harvest Scenario 1 (interactions on, groundfish $h=0.3$, groundfish $r=0.45$ ), final biomass for pelagic fishes was higher than for demersal fishes (Fig. 3b) compared to combination Scenario 4 (Fig. 3a).


Fig. 2. Proportional losses to biomass in Scenario $8(h=0.1$; interactions present; climate on-groundfish $r=0.405$ ) in the combination class of scenarios: (a) groundfishes, (b) elasmobranchs, (c) pelagics

In targeted harvest Scenario 2 (interactions on, elasmobranch $h=0.3$, groundfish $r=0.45$ ) there was less of a difference in pelagic and demersal final biomass (Fig. 3c) than in combination Scenario 4 (Fig. 3a), and in targeted harvest Scenario 3 (interactions on, small pelagic $h=0.3$, groundfish $r=0.45$ ), the modeled ecosystem was dominated more by demersal biomass (Fig. 3d) than in combination Scenario 4 (Fig. 3a). 
These results are primarily due to the increased harvest on a specific group, combined with the trophodynamic interactions (predation and competition) between the groups.

(2) Groundfishes and small pelagics achieved a $B_{\text {final }} / B_{\mathrm{MSY}}$ ratio greater than 1.0 in all scenarios except when they were targeted at the higher harvest rate (Table 5), while elasmobranchs were below a $B_{\text {final }} / B_{\mathrm{MSY}}$ ratio of 1.0 in all scenarios. These results are primarily due to the susceptibility of elasmobranchs to harvest relative to the other groups because of their lower growth rate compared to the other 2 groups. The higher harvest rate when applied to groundfishes and small pelagics was enough to lower their respective $B_{\text {final }} / B_{\mathrm{MSY}}$ ratios below 1.0: groundfishes to a ratio of 0.32 in Scenario 1 (no climate effects) and to 0.21 in Scenario 2 (with climate effects), and pelagics to a ratio of 0.41 in Scenarios 3 (without climate effects) and 6 (with climate effects).

(3) When the targeted harvest was on a group that was parameterized with strong interactions on another group, the second group had a higher final biomass and $B_{\text {final }} / B_{\mathrm{MSY}}$ ratio than otherwise, due to competitive or predatory release. Small pelagics had the highest final $B_{\text {final }} / B_{\text {MSY }}$ ratio when elasmobranchs were targeted, due to predatory release. Groundfishes and elasmobranchs had their highest final $B_{\text {final }} / B_{\mathrm{MSY}}$ ratio in the scenario in which the other group was targeted, due to competitive release (Table 5).

(4) The total system $B_{\text {final }} / B_{\mathrm{MSY}}$ ratio was higher than 1.0 only when elasmobranchs were preferentially targeted. This resulted because of the combination of predatory release on small pelagics and competitive release on groundfishes (Table 5). This also reflects compensatory dynamics from a systemic perspective.

When climate effects were present (groundfish $r=$ 0.405), the main response was a generally reduced groundfish biomass and $B_{\text {final }} / B_{\mathrm{MSY}}$ ratio compared to the non-climate scenarios (Table 5). The largest relative change occurred in Scenario 4 (interactions present, groundfish $h=0.3$, groundfish $r=0.405$ ), with a $33 \%$ decrease in groundfish final biomass and corresponding $B_{\text {final }} / B_{\mathrm{MSY}}$ ratio compared to Scenario 1 (same but with no climate effects; groundfish $r=0.45$ ).

Fig. 3. Effects on the demersal and pelagic fish communities of the targeted harvest class of scenarios with interactions on, but climate effects turned off: (a) triad combinatory Scenario 1 (interactions on, $h=0.1$, climate off-groundfish $r=$ 0.45), (b) targeted harvest Scenario 1 (groundfishes targeted at $h=0.3$ ), (c) targeted harvest Scenario 2 (elasmobranchs targeted at $h=0.3$ ), (d) targeted harvest Scenario 3 (pelagics targeted at $h=0.3$ )
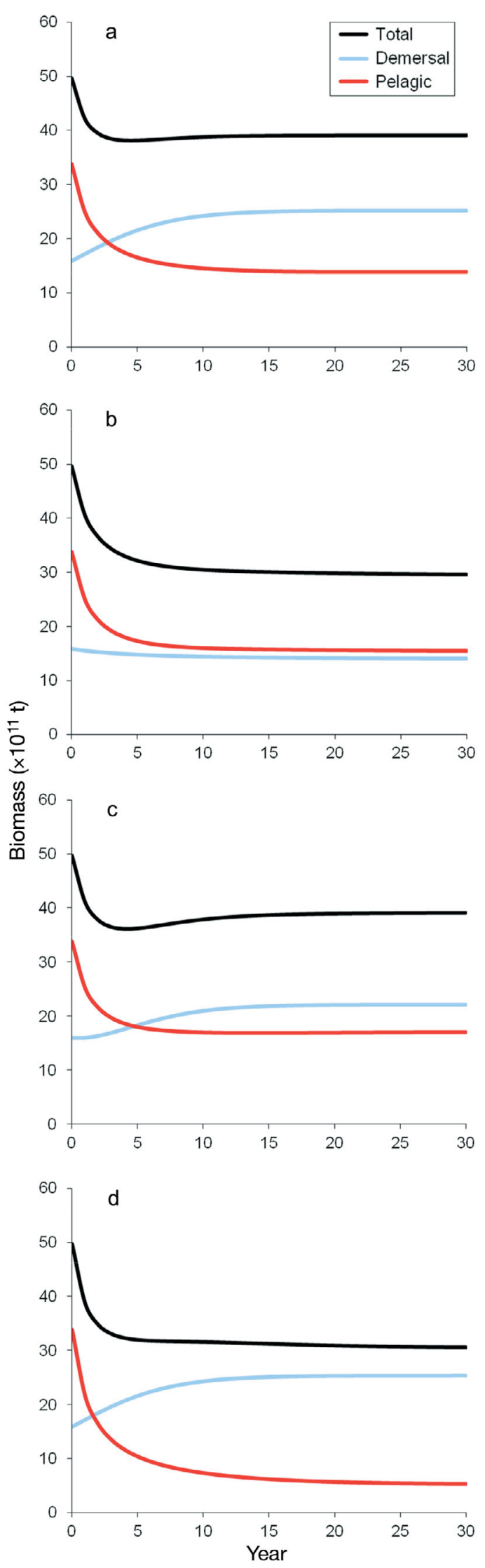
Table 5. Summary of targeted harvest scenarios of final biomass to biomass at maximum sustainable yield $\left(B_{\text {final }} / B_{\mathrm{MSY}}\right)$ ratios. The targeted group had its harvest rate set to 0.3 , while the other 2 groups had their harvest rates set to 0.1 . Bold values are $<1$, indicating that this group did not reach the group $B_{\mathrm{MSY}}$

\begin{tabular}{|lllllll|}
\hline \multirow{2}{*}{ Scenario Harvested group } & Climate & \multicolumn{5}{c}{ Targeted harvest $B_{\text {final }} / B_{\text {MSY }}-$} \\
& & & $\begin{array}{c}\text { Ground- } \\
\text { fishes }\end{array}$ & $\begin{array}{c}\text { Elasmo- } \\
\text { branchs }\end{array}$ & $\begin{array}{c}\text { Small } \\
\text { pelagics }\end{array}$ & System \\
\hline 1 & Groundfishes & $\mathrm{N}$ & $\mathbf{0 . 3 2}$ & $\mathbf{0 . 8 3}$ & 1.20 & $\mathbf{0 . 7 6}$ \\
2 & Elasmobranchs & $\mathrm{N}$ & 1.55 & $\mathbf{0 . 0 1}$ & 1.31 & 1.01 \\
3 & Pelagics & $\mathrm{N}$ & 1.24 & $\mathbf{0 . 6 6}$ & $\mathbf{0 . 4 1}$ & $\mathbf{0 . 7 9}$ \\
4 & Groundfishes & $\mathrm{Y}$ & $\mathbf{0 . 2 1}$ & $\mathbf{0 . 8 5}$ & 1.21 & $\mathbf{0 . 7 3}$ \\
5 & Elasmobranchs & $\mathrm{Y}$ & 1.50 & $\mathbf{0 . 0 1}$ & 1.32 & $\mathbf{0 . 9 9}$ \\
6 & Pelagics & $\mathrm{Y}$ & 1.19 & $\mathbf{0 . 6 8}$ & $\mathbf{0 . 4 1}$ & $\mathbf{0 . 7 8}$ \\
\hline
\end{tabular}

While harvest had the largest impact on biomass losses of groundfishes for the first half of the model run, climate eventually became the dominant cause of biomass losses. Species interactions stayed relatively consistent in their impacts on groundfish biomass loss over the model run (Fig. 4). Additionally, pelagic and elasmobranch $B_{\text {final }} / B_{\mathrm{MSY}}$ ratios increased in the scenarios where climate was present (Scenarios 4-6; groundfish $r=0.405$ ) due to decreased predation and competition effects on the 2 groups, respectively (Table 5).

\section{System harvest scenarios}

In the system harvest scenarios where the harvest level for all groups was set to 7 different values (Scenarios 1-7; 0, 0.01, 0.05, 0.1, 0.2, 0.3, 0.5), species interactions were turned on, and climate was toggled off (groundfish $r=0.45$ ), each of the 3 groups showed different responses to increasing harvest (Table 6). Elasmobranchs decreased in biomass at each increase in harvest level and fell below a $B_{\text {final }} / B_{\mathrm{MSY}}$ ratio of 1.0 in all scenarios where the system harvest rate was 0.1 or greater (Scenarios 4-7).

Groundfish biomass remained stable when the harvest rate was between 0 and 0.1 (Scenarios 1-4) and only fell below a $B_{\text {final }} / B_{\mathrm{MSY}}$ ratio of 1.0 at a harvest rate of 0.3 or higher (Scenarios 6 and 7). This 'delay' was likely due to competitive release as elasmobranch biomass did drop at the lower harvest rates $(h=0.01$ to 0.1$)$.

Small pelagic biomass actually increased slightly through the first 4 levels of harvest rates $(0-0.1)$, likely due to predatory release by elasmobranchs. Due to their higher growth rate, they ended with a higher final biomass and $B_{\text {final }} / B_{\mathrm{MSY}}$ ratio than groundfishes at the higher harvest levels $(0.3,0.5)$. Because of the indirect interaction effects combined with har- vest rates, the small pelagics had a $B_{\text {final }} / B_{\mathrm{MSY}}$ ratio above 1.0 at the moderate harvest levels $(0.05,0.1,0.2)$ but not at the lower or higher harvest rates $(0,0.01,0.3,0.5)$. Finally, the system $B_{\text {final }} / B_{\text {MSY }}$ ratio fell below 1.0 at a harvest rate of 0.2 or higher (Scenarios 5-7), largely driven by the small pelagic biomasses.

When the effects of climate were added (groundfish $r=0.405$ ) in Scenarios 8 to 14, 4 main results occurred (Tables 6 \& 7). Groundfishes fell below a $B_{\text {final }} / B_{\text {MSY }}$ ratio of 1.0 at a harvest rate of 0.182 , instead of a harvest rate of 0.212 as in the system harvest scenarios without climate effects (Table 6 only shows the scenarios described above; further runs were done to more precisely define the ratio's tipping point). Similarly, the system $B_{\text {final }} / B_{\mathrm{MSY}}$ ratio fell below 1.0 at a harvest rate of 0.098 , compared to a harvest rate of 0.104 in the system harvest scenarios without climate effects. The percentage of final biomass compared to the corresponding system harvest scenario without climate effects decreased for groundfish as harvest rates increased (from $\sim 100 \%$ at harvest rates of 0 and 0.01 to $35.7 \%$ at a harvest rate of 0.5 ; Table 7 ). The other groups showed a minor increase in their final biomass and $B_{\text {final }} / B_{\mathrm{MSY}}$ ratio compared to the system harvest scenarios, likely due to competitive release of elasmobranchs and an overall lowering of predation on small pelagics.

Losses to groundfish biomass varied over the range of harvest rates explored when climate effects were present (Fig. 5). At low levels of harvest $(h=0.01$

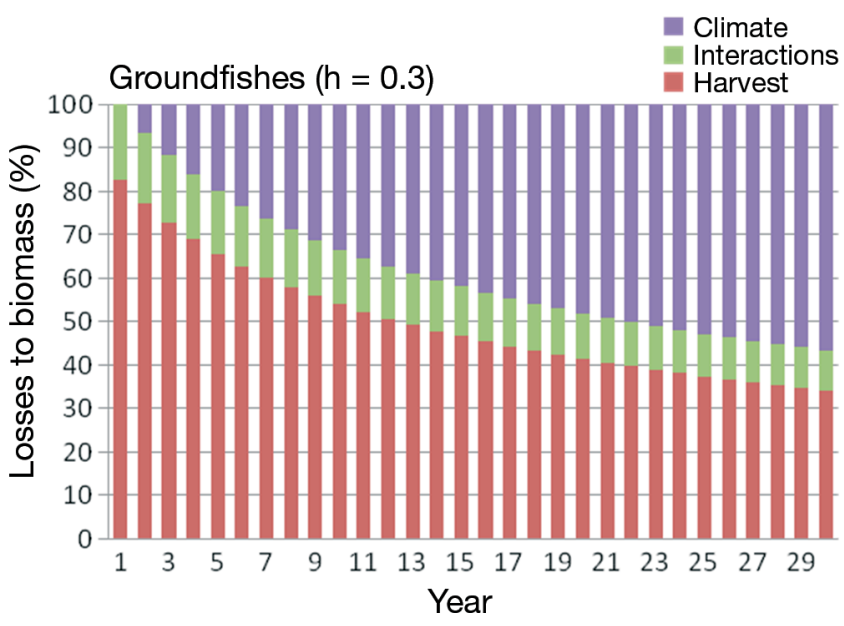

Fig. 4. Proportional losses to biomass of groundfishes according to the targeted harvest of groundfishes $(h=0.3)$ scenario 
Table 6. Summary of system harvest scenarios of final biomass to biomass at maximum sustainable yield $\left(B_{\text {final }} / B_{\mathrm{MSY}}\right)$ ratios. Bold values are $<1$, indicating that this group did not reach the group $B_{\mathrm{MSY}}$

\begin{tabular}{|lllllll|}
\hline \multirow{2}{*}{ Scenario } & \multirow{2}{*}{ Harvested } & \multicolumn{5}{c}{ System harvest $B_{\text {final }} / B_{\text {MSY }}$} \\
\cline { 3 - 6 } & & Climate & $\begin{array}{c}\text { Ground- } \\
\text { fishes }\end{array}$ & $\begin{array}{c}\text { Elasmo- } \\
\text { branchs }\end{array}$ & $\begin{array}{c}\text { Small } \\
\text { pelagics }\end{array}$ & System \\
\hline 1 & 0 & $\mathrm{~N}$ & 1.26 & 1.60 & $\mathbf{0 . 9 5}$ & 1.26 \\
2 & 0.01 & $\mathrm{~N}$ & 1.26 & 1.49 & $\mathbf{0 . 9 6}$ & 1.23 \\
3 & 0.05 & $\mathrm{~N}$ & 1.27 & 1.09 & 1.02 & 1.13 \\
4 & 0.1 & $\mathrm{~N}$ & 1.25 & $\mathbf{0 . 6 4}$ & 1.07 & 1.01 \\
5 & 0.2 & $\mathrm{~N}$ & 1.04 & $\mathbf{0 . 1 2}$ & 1.03 & $\mathbf{0 . 7 6}$ \\
6 & 0.3 & $\mathrm{~N}$ & $\mathbf{0 . 6 5}$ & $\mathbf{0 . 0 1}$ & $\mathbf{0 . 8 4}$ & $\mathbf{0 . 5 2}$ \\
7 & 0.5 & $\mathrm{~N}$ & $\mathbf{0 . 0 4}$ & $\mathbf{0 . 0 0}$ & $\mathbf{0 . 3 3}$ & $\mathbf{0 . 1 2}$ \\
8 & 0 & $\mathrm{Y}$ & 1.26 & 1.60 & $\mathbf{0 . 9 5}$ & 1.26 \\
9 & 0.01 & $\mathrm{Y}$ & 1.26 & 1.50 & $\mathbf{0 . 9 6}$ & 1.23 \\
10 & 0.05 & $\mathrm{Y}$ & 1.24 & 1.10 & 1.02 & 1.13 \\
11 & 0.1 & $\mathrm{Y}$ & 1.20 & $\mathbf{0 . 6 5}$ & 1.08 & $\mathbf{0 . 9 9}$ \\
12 & 0.2 & $\mathrm{Y}$ & $\mathbf{0 . 9 3}$ & $\mathbf{0 . 1 3}$ & 1.05 & $\mathbf{0 . 7 3}$ \\
13 & 0.3 & $\mathrm{Y}$ & $\mathbf{0 . 4 9}$ & $\mathbf{0 . 0 1}$ & $\mathbf{0 . 8 8}$ & $\mathbf{0 . 4 8}$ \\
14 & 0.5 & $\mathrm{Y}$ & $\mathbf{0 . 0 1}$ & $\mathbf{0 . 0 0}$ & $\mathbf{0 . 3 4}$ & $\mathbf{0 . 1 2}$ \\
\hline
\end{tabular}

Generally, when harvest occurred, it had the strongest effect on each group, particularly on elasmobranchs due to their low growth rate. Groundfishes were also strongly affected, starting at moderate levels of harvest $(h=$ 0.2 to 0.3 ), but less so than elasmobranchs-due to the higher growth rate for the groundfish functional group. Additionally, release of competitive effects when elasmobranchs were also fished at the same level tended to keep groundfish - and therefore system-biomass more stable at lower levels of harvest. Finally, small pelagics were least affected by harvest $(h<0.2)$, due to a combination of having the highest growth rate among the 3 groups, and because of the predatory release as groundfish and and 0.05), losses to biomass for the groundfish group were mostly from interactions with elasmobranchs (Fig. 5a,b). At $h=0.1$, harvest accounted for a bit less than half of the losses to biomass, with interactions and climate effects approximately equal (Fig. 5c). At $h=0.2$ and above, elasmobranchs were greatly reduced in biomass, leaving harvest and climate effects as the dominant losses to biomass for groundfishes (Fig. 5d). At $h=0.3$ and 0.5 (Fig. 5e,f), harvest effects were strongest in the first few years, before climate effects become dominant (about $50 \%$ of losses to biomass came from climate at $h=0.3$ after about Year 17 , and greater than $75 \%$ of the losses to biomass came from climate at $h=0.5$ by Year 30).

\section{DISCUSSION}

As might be expected, the relative importance among the triad of drivers differed among the 3 functional groups, and under different harvest scenarios.

Table 7. System harvest. Percentage of final biomass when climate effects were turned on compared to turned off

\begin{tabular}{|lcccc|}
\hline Harvest & Groundfishes & $\begin{array}{c}\text { Elasmo- } \\
\text { branchs }\end{array}$ & $\begin{array}{c}\text { Small } \\
\text { pelagics }\end{array}$ & System \\
\hline 0 & 100.1 & 100.0 & 99.9 & 100.0 \\
0.01 & 99.6 & 100.1 & 100.0 & 99.9 \\
0.05 & 97.8 & 100.7 & 100.2 & 99.4 \\
0.1 & 95.5 & 102.0 & 100.6 & 98.6 \\
0.2 & 89.6 & 105.7 & 102.1 & 96.0 \\
0.3 & 76.6 & 108.0 & 103.9 & 91.5 \\
0.5 & 35.7 & 102.5 & 102.0 & 94.4 \\
\hline
\end{tabular}

elasmobranch biomass declined. These results are similar to those seen in previous studies which showed compensatory dynamics in the NEUS LME (Fogarty \& Murawski 1998, Auster \& Link 2009).

Ecological interactions had the strongest overall effect on small pelagics (predation from both of the other 2 groups), and a moderate effect on groundfish (competition from the elasmobranchs). Elasmobranchs were less strongly affected by competition from groundfish. Climate effects, since they targeted groundfish specifically in our model, primarily resulted in a decrease in groundfish biomass when applied, with a corresponding increase in elasmobranch and, in some scenarios, pelagic biomass, due to competitive and predatory release, respectively. The interplay among these factors, as simulated here, demonstrates that the prominence of any driver can shift given the dynamics and magnitude among the others.

When comparing the effects of the triad of drivers on each group, small pelagics were most strongly affected by ecological interactions, then harvest, and then climate. Elasmobranchs were most strongly affected by harvest, then ecological interactions, and finally climate. Groundfishes, however, appeared to be notably affected by all 3 drivers. Obviously as harvest increased in any class of scenarios, its effect became increasingly dominant, and as long as elasmobranchs remained at relatively high biomass, the corresponding ecological interactions also had a large impact on groundfish biomass losses. Climate tended to also have a stronger effect at higher harvest levels in our scenarios - indicating that climate effects may be more important in heavily exploited 

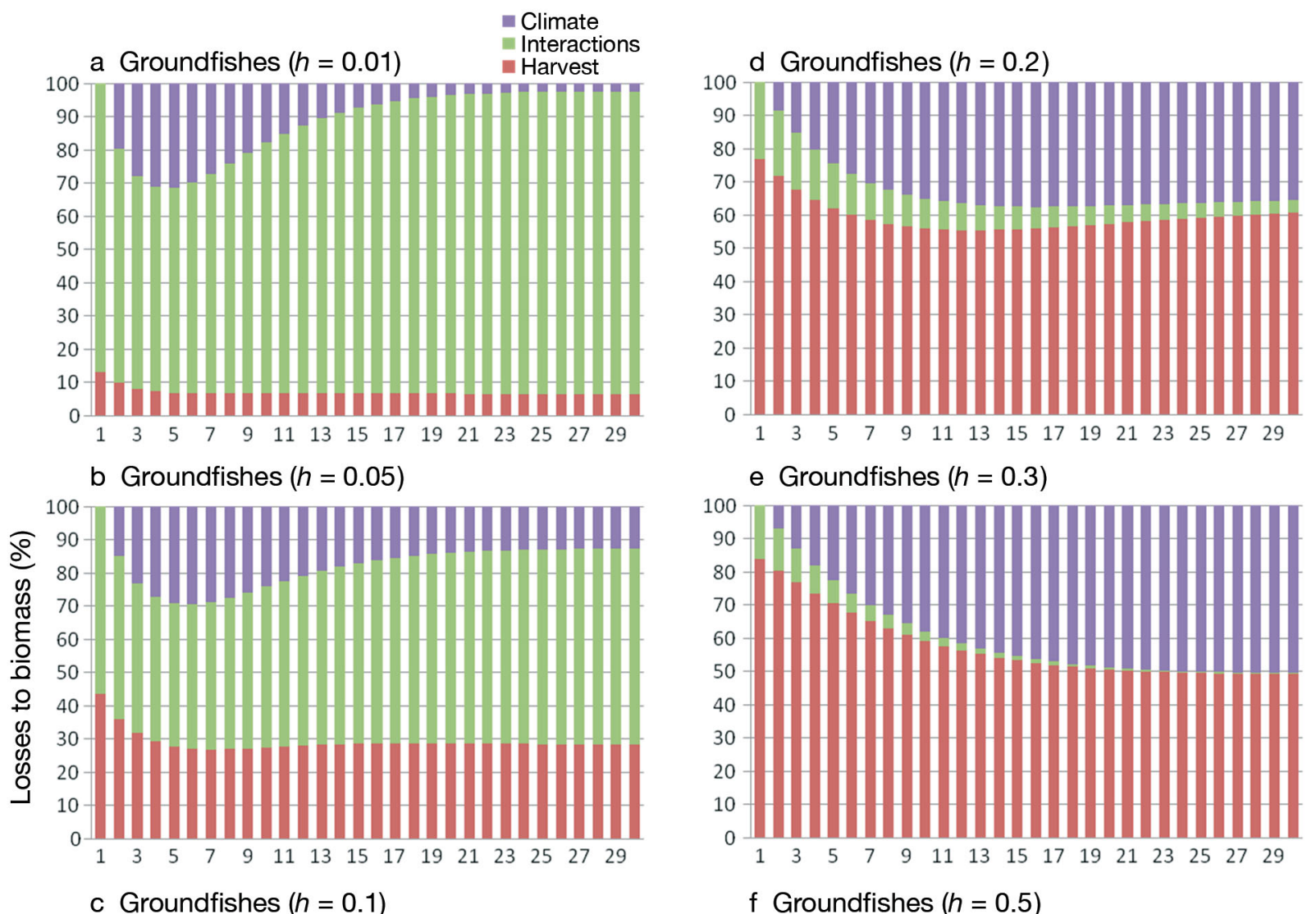

e Groundfishes $(h=0.3)$
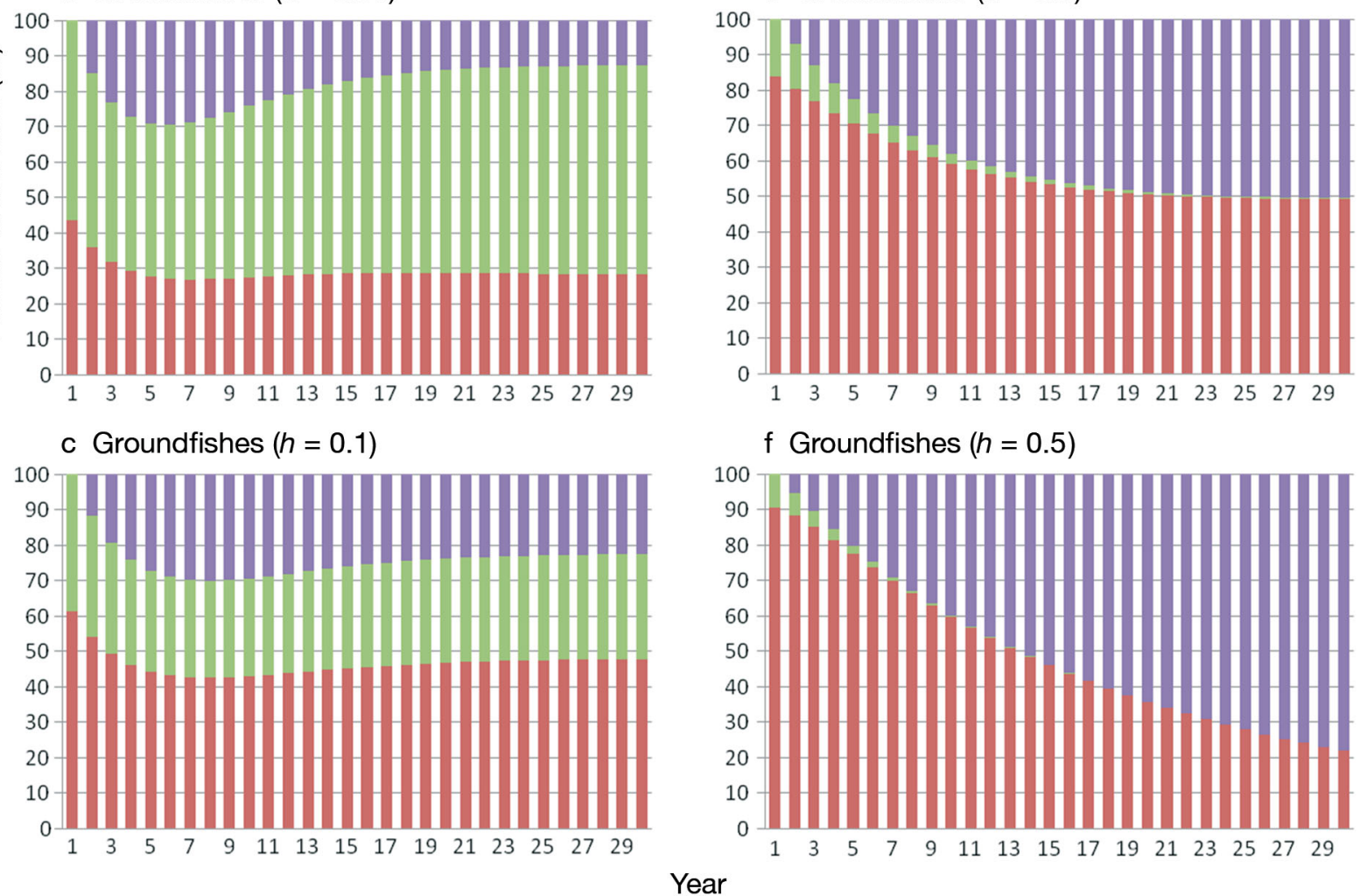

Fig. 5. Proportional losses to biomass of groundfishes caused by the system harvest class of scenarios with climate effects on (groundfish $r=0.405$ ) where harvest was set to: (a) 0.01 , (b) 0.05 , (c) 0.1 , (d) 0.2 , (e) 0.3 , (f) 0.5

ecosystems than in ones with lower levels of exploitation. These results, while simulation only, are confirmed by other empirical and modeling studies (e.g. Mackinson et al. 2008, Blanchard et al. 2010, Coll et al. 2010, Link et al. 2010a, Shin et al. 2010a,b, Tyrrell et al. 2011).

There are some important implications that come from these results. Depending on the life history of the groups, each of the triad of drivers can have very different impacts on each of the groups. Since harvest was the only driver of the 3 that was toggled at different ranges, the relative effects of the triad of drivers in our scenarios is dependent on the level of harvest for each group. It is also important to be careful in choosing the component species of each aggregate group, as a group with widely varying growth rates or other characteristics can create issues of interpretation in the results. While we maintain that it is likely the group as a whole would react with relative stability, the individual species within that group might not do so (see Auster \& Link 2009, Gaichas et al. 2012). Other implications from our 
models relate to harvest levels. For instance, $h>0.3$ for any group results in the group as a whole having a $B_{\text {final }} / B_{\mathrm{MSY}}$ ratio less than 1.0 , while $h=0.1$ results in groups with moderate (groundfishes) or high (small pelagics) growth rates having a $B_{\text {final }} / B_{\mathrm{MSY}}$ ratio above 1.0. The effects of climate further lower the exploitation rate at which this ratio drops below 1.0 for groundfish, indicating that a more precautionary exploitation rate should be considered under climate change. While we do not recommend these as universal basic properties of ecosystems, even for the NEUS LME, we do suggest that this kind of MSE could explore such recommendations, given a properly fitted ASP which incorporates climate and trophodynamic effects. Obviously the choice of parameter values (particularly $r$ ) greatly affects the results and the relative importance, but we think that our results generally demonstrate the utility of such an approach.

One of the strengths of our approach is that models like AGG-PROD can elucidate the effects of the triad of drivers on biological reference points (BRPs). While one might qualitatively be able to predict the effects of some of the drivers in isolation on individual groups with no interactions between them, we think that once multiple drivers (climate, interactions, and fishing) are occurring at the same time, a model such as AGG-PROD is very valuable, and needed, in separating their effects on fish populations. Even though we explored only a comparison of final biomass to $B_{\mathrm{MSY}}$, there are some general conclusions we can draw. The most important might be that in the presence of strong impacts from climate or ecological interactions, the effects of setting $F$ to any reference level are difficult to predict. Decreasing the predators through increased harvest can cause forage fish to increase in some cases, but in other cases interactions between predator groups, and differential effects of harvest on them, could result in more complex effects which might be counterintuitive. Climate and environmental effects also have varying impacts on the system, which should be taken into account. Therefore, we propose that if trophodynamic and climate effects are not explicitly included in models which determine BRPs, a more conservative approach should be taken in estimating these BRPs. An important consideration in this approach is that the precision possible in this model for defining BRPs (and the harvest rates corresponding to those BRPs) is likely much greater than could realistically be differentiated in an actual management setting. This will need to be further explored when using these models in a management context beyond a management strategy type of approach.
ASPs like AGG-PROD can be very flexible and valuable tools. For instance, one use is as an operating model in an MSE context. While certain classes of management actions are more difficult to simulate (e.g. spatial management) using ASPs, these models can be easily extended to include ecological interactions and climate effects. In some cases, as we did with groundfish growth rates, a simple modification to a parameter (e.g. $r$ or $K$ ) can approximate certain climate effects such as range contraction or population size (Attrill \& Power 2002, Nye et al. 2009). Additionally, empirical and modeling studies have shown linkages between growth rates and climate change (Brander 1995, O'Brien et al. 2000, Clark et al. 2003), supporting this approach. Work to further develop this modeling approach will include fitting model parameters to data, sensitivity analyses, and introducing stochasticity representing environmentally driven pressures on the fish populations. Additionally, exploring differential application of harvest rates across the different groups is a logical next step, especially in conjunction with exploring scenarios in a management context of tradeoffs between yield and ecosystem objectives. Ultimately, this model can be used to explore impacts on ecosystem function and yield under multiple strategies (e.g. proportional harvest rates based on productivity of the different stocks versus selective fishing) (Garcia 2011, Rochet et al. 2011).

Aggregating groups as part of a surplus production model has certain benefits. Many important fisheries are multi-species fisheries, such as those which target groundfishes in the NEUS LME, the North Sea, Southeast Australia, and similar temperate shelf systems (ICES 1993, Smith 1994, CEFAS 2001), all of which have management plans that reflect this multispecies targeting. An ASP can easily explore the effects from the triad of drivers on a level that multi-species fisheries operate. Aggregate groups also tend to be more stable than the individual components (Fogarty \& Murawski 1998, Auster \& Link 2009), so this method can be used initially to determine robust harvest levels to achieve system and aggregate group level BRPs. More complex models which explicitly include multiple species can then be used to examine the implications of those harvest strategies on the individual components of an aggregated group (as was done by Gaichas et al. 2012). This 2-stage approach is also recommended due to the observation that aggregated models may have very different characteristics regarding community stability, resilience, and other behaviors of the components modeled, than one in which the components are disaggregated (Pinnegar et al. 2005). 
An ASP model could also be used to provide a precautionary cap on biological reference points determined by a suite of single-species models. Since it has been shown through multi-species and ecosystem modeling exercises (Au 1973, Pope 1979, Collie \& Gislason 2001, Walters et al. 2005, Mueter \& Megrey 2006, NEFSC 2008) and other analyses (May 1975, Pope 1975, Brown et al. 1976, Fukuda 1976, May et al. 1979, Gislason et al. 2010, Tyrrell et al. 2011) that the sum of single-species MSYs can be quite different than the MSY of the corresponding multispecies group, we suggest that BRPs resulting from an ASP model could be utilized as the maximum total amount that should be removed from the group. A further consideration is that by not directly modeling species interactions in our model, we would expect differences in the estimated BRPs in our approach compared to a model in which those interactions were present explicitly. As an example, not all species in the groundfish group would be affected equally by climate-in fact there might be species which would show increased growth rates. Thus, while we recommend ASPs as useful operating models, they should be applied with an understanding of their limitations as well as their strengths. Particularly we recommend that they be part of a toolbox of models rather than the sole operating model in an MSE.

With EBFM emerging (NMFS 1999, Link 2002a,b, Pikitch et al. 2004, Link 2010), there is a need for tools and methods that can evaluate the triad of drivers in an MSE context (Link et al. 2010b,c), particularly in the context of multi-species fisheries. We think that the utility of ASPs with trophic interactions and climate effects modeled explicitly can be an important element of EBFM by providing aggregate level reference points and as operating models in an MSE context to explore the possible effects of changes in climate and the trophic structure of a fish community. We recommend that they be used with other models, particularly multi-species models which also include the triad of drivers explicitly, to fully explore the dynamics of not only the aggregate groups of interest to a fishery or management, but also the entire system and the individual component species within that system.

Acknowledgements. This collaborative, multilateral work was funded through the U.S. Comparative Analysis of Marine Ecosystem Organization (CAMEO), the Norwegian Research Council (NRC), and the Fishery and Oceans Canada Ecosystem Research Initiative (ERI). Major national institutes (DFO, IMR, NMFS) also contributed significant inkind and directed resources to this project. This work is also endorsed by ESSAS. The work we report upon herein resulted from several joint meetings, particularly the Sur- plus Production Modeling Workshop (SPMW 1 \& 2) and associated inter-cessional efforts, representing a continuation of and follow-on to other joint workshops, including Canadian and US Ecosystems (CANUSE I \& II), Marine Ecosystems of Norway and the US (MENU I \& II), and Norwegian-Canadian Collaborations (NORCAN). Finally, we dedicate this work to the memory of Bern Megrey, who was an integral part of these efforts and whose untimely death was unfortunate but whose enthusiasm for this work was invaluable.

\section{LITERATURE CITED}

Adkison MD (2009) Drawbacks of complex models in frequentist and Bayesian approaches to natural resource management. Ecol Appl 19:198-205

Anderson PJ, Piatt JF (1999) Community reorganization in the Gulf of Alaska following ocean climate regime shift. Mar Ecol Prog Ser 189:117-123

Applegate A, Cadrin S, Hoenig J, Moore C, Murawski S, Pikitch E (1998) Evaluation of existing overfishing definitions and recommendations for new overfishing definitions to comply with the Sustainable Fisheries Act. Final report. Overfishing Definition Review Panel, New England Fishery Management Council, Newburyport, MA

Attrill MJ, Power M (2002) Climatic influence on a marine fish assemblage. Nature 417:275-278

Au DWK (1973) Total sustainable yield from Subareas 5 and 6 based on yield per recruit and primary production consideration. ICNAF Research Document 73/10. Serial No. 2912. ICNAF, Dartmouth, NS

Auster PJ, Link JS (2009) Compensation and recovery of feeding guilds in a northwest Atlantic shelf fish community. Mar Ecol Prog Ser 382:163-172

Bax NJ (1991) A comparison of the fish biomass flow to fish, fisheries, and mammals in six marine ecosystems. ICES Mar Sci Symp 193:217-224

Bax NJ (1998) The significance and prediction of predation in marine fisheries. ICES J Mar Sci 55:997-1030

> Beaugrand G, Brander KMS, Souissi LJ, Reid PC (2003) Plankton effect on cod recruitment in the North Sea. Nature 426:661-664

Blanchard JL, Coll M, Cotter J, Link J and others (2010) Trend analysis of indicators: a comparison of recent changes in the status of marine ecosystems around the world. ICES J Mar Sci 67:732-744

Brander KM (1995) The effect of temperature on the growth rate of Atlantic cod (Gadus morhua L.). ICES J Mar Sci 52:1-10

Brown B, Breenan J, Grosslein M, Heyerdahl E, Hennemuth $R$ (1976) The effect of fishing on the marine finfish biomass in the northwest Atlantic from the Gulf of Maine to Cape Hatteras. ICNAF Res Bull 12:49-68

Bundy A, Bohaboy EC, Hjermann DO, Mueter FJ, Fu C, Link JS (2012) Common patterns, common drivers: comparative analysis of aggregate surplus production across ecosystems. Mar Ecol Prog Ser 459:203-218

CEFAS (Centre for the Environment, Fisheries and Aquaculture Science) (2001) Fisheries information — cod, haddock, saithe and whiting in the North Sea. CEFAS, Lowestoft

Chassot E, Bonhommeau S, Dulvy NK, Melin F, Watson R, Gascuel D, Le Pape O (2010) Global marine primary production constrains fisheries catches. Ecol Lett 13:495-505

> Chavez FP, Ryan J, Lluch-Cota SE, Niquen M (2003) From anchovies to sardines and back: multidecadal change in the Pacific Ocean. Science 299:217-221 
Christensen V (1996) Managing fisheries involving predator and prey species. Rev Fish Biol Fish 6:417-442

Clark RA, Fox CJ, Viner D, Livermore M (2003) North sea cod and climate change-modelling the effects of temperature on population dynamics. Glob Change Biol 9: 1669-1680

> Coll M, Shannon LJ, Yemane D, Link J and others (2010) Ranking ecological relative status of exploited ecosystems using multiple indicators. ICES J Mar Sci 67:769-786

Collie JS, DeLong AK (1999) Multispecies interactions in the Georges Bank fish community. In: Ecosystem approaches for fisheries management. AK-SG-99-01. Alaska Sea Grant College Program, Fairbanks, AK, p 187-210

Collie JS, Gislason H (2001) Biological reference points for fish stocks in a multispecies context. Can J Fish Aquat Sci 58:2167-2176

Constable AJ (2001) The ecosystem approach to managing fisheries: achieving conservation objectives for predators of fished species. CCAMLR Sci 8:37-64

> Costanza R, Sklar FH (1985) Articulation, accuracy, and effectiveness of ecological models: a review of freshwater wetland applications. Ecol Model 27:45-68

> Daskalov GM, Grishin AN, Rodionov S, Mihneva V (2007) Trophic cascades triggered by overfishing reveal possible mechanisms of ecosystem regime shifts. Proc Natl Acad Sci USA 104:10518-10523

> Deriso RB (1980) Harvesting strategies and parameter estimation for an age-structured model. Can J Fish Aquat Sci 37:268-282

> Duplisea DE, Blanchard F (2005) Relating species and community dynamics in a heavily exploited marine fish community. Ecosystems 8:899-910

Fogarty MJ, Murawski SA (1998) Large-scale disturbance and the structure of marine systems: fishery impacts on Georges Bank. Ecol Appl 8:S6-S22

Frank KT, Petrie B, Choi JS, Leggett WC (2005) Trophic cascades in a formerly cod-dominated ecosystem. Science 308:1621-1623

Fukuda Y (1976) A note on yield allocation in multi-species fisheries. ICNAF Res Bull 12:83-87

- Fulton EA, Smith ADM, Johnson CR (2003) Effect of complexity on marine ecosystem models. Mar Ecol Prog Ser 253:1-16

Fulton EA, Link JS, Kaplan IC, Savina-Rolland $M$ and others (2011) Lessons in modelling and management of marine ecosystems: the Atlantis experience. Fish Fish 12(2): 171-188

Gaichas S, Gamble R, Fogarty M, Benoit H and others (2012) Assembly rules for aggregate-species production models: simulations in support of management strategy evaluation. Mar Ecol Prog Ser 459:275-292

Gamble RJ, Link JS (2009) Analyzing the tradeoffs among ecological and fishing effects on an example fish community: a multispecies (fisheries) production model. Ecol Model 220:2570-2582

Garcia SM (ed) (2011) Selective fishing and balanced harvest in relation to fisheries and ecosystem sustainability. Report of a scientific workshop organized by the IUCNCEM Fisheries Expert Group (FEG) and the European Bureau for Conservation and Development (EBCD) in Nagoya (Japan), 14-16 October 2010. IUCN, Gland

Gislason H, Daan N, Rice JC, Pope JG (2010) Size, growth, temperature and the natural mortality of marine fish. Fish Fish 11:149-158

Graham M (1935) Modern theory of exploiting a fishery and application to the North Sea trawling. J Cons Int Explor Mer 10:264-274
Hannah C, Vezina A, St John M (2010) The case for marine ecosystem models of intermediate complexity. Prog Oceanogr 84:121-128

Hilborn R, Walters CJ (1992) Quantitative fisheries stock assessment: choice, dynamics and uncertainty. Chapman \& Hall, New York, NY

Hollowed AB, Bax N, Beamish R, Collie J and others (2000) Are multispecies models an improvement on singlespecies models for measuring fishing impacts on marine ecosystems? ICES J Mar Sci 57:707-719

ICES (International Council for the Exploration of the Sea) (1993) Report of ICES working group on the assessment of demersal stocks in the North Sea and Skagerrak. CM 1993/Assess:5. ICES, Copenhagen

Jackson JBC, Kirby MX, Berger WH, Bjorndal KA and others (2001) Historical overfishing and the recent collapse of coastal ecosystems. Science 293:629-637

> Jacobson LD, Bograd SJ, Parrish RH, Mendelssohn R, Schwing FB (2005) An ecosystem-based hypothesis for climatic effects on surplus production in California sardine (Sardinops sagax) and environmentally dependent surplus production models. Can J Fish Aquat Sci 62: 1782-1796

Keyl F, Wolff M (2008) Environmental variability and fisheries: What can models do? Rev Fish Biol Fish 18:273-299

Link JS (2002a) Ecological considerations in fisheries management: When does it matter? Fisheries 27:10-17

Link JS (2002b) What does ecosystem-based fisheries management mean? Fisheries 27:18-21

Link JS (2010) Ecosystem-based fisheries management: confronting tradeoffs. Cambridge University Press, New York, NY

Link JS, Almeida FP (2000) An overview and history of the Food Web Dynamics Program of the Northeast Fisheries Science Center, Woods Hole, Massachusetts. NOAA Tech Memo NMFS-NE-159. NEFSC, Woods Hole, MA

Link JS, Yemane D, Shannon LJ, Coll M, Shin YJ, Hill L, de Fatima Borges M (2010a) Relating marine ecosystem indicators to fishing and environmental drivers: an elucidation of contrasting responses. ICES J Mar Sci 67: 787-795

Link JS, Ihde TF, Townsend H, Osgood K and others (eds) (2010b) Report of the 2nd national ecosystem modeling workshop (NEMoW II): bridging the credibility gapdealing with uncertainty in ecosystem models. NOAA Tech Memo NMFS-F/SPO-102. NOAA, National Marine Fisheries Service, Silver Spring, MD

Link JS, Megrey BA, Miller TJ, Essington $\mathrm{T}$ and others (2010c) Comparative analysis of marine ecosystems: international production modeling workshop. Biol Lett 6: 723-726

Link JS, Gaichas S, Miller TJ, Essington T and others (2012) Synthesizing lessons learned from comparing fisheries production in 13 northern hemisphere ecosystems: emergent fundamental features. Mar Ecol Prog Ser 459: 293-302

Lucey SM, Nye JA (2010) Shifting species assemblages in the Northeast US Continental Shelf Large Marine Ecosystem. Mar Ecol Prog Ser 415:23-33

Lucey SM, Cook AM, Boldt JL, Link JS, Essington TE, Miller TJ (2012) Comparative analyses of surplus production dynamics of functional feeding groups across 12 northern hemisphere marine ecosystems. Mar Ecol Prog Ser 459:219-229

> Ludwig D, Walters CJ (1985) Are age-structured models appropriate for catch-effort data? Can J Fish Aquat Sci 42:1066-1072 
Ludwig D, Walters CJ (1989) A robust method for parameter estimation from catch and effort data. Can J Fish Aquat Sci 46:137-144

Mackinson S, Daskalov G, Heymans S, Neira S and others (2008) Which forcing factors fit? Using ecosystem models to investigate the relative influence of fishing and changes in primary productivity on the dynamics of marine ecosystems. Ecol Model 220:2972-2987

May AW (1975) Report of standing committee on research and statistics. ICNAF Seventh Special Commission Meeting - September 1975, Dartmouth, NS

May RM, Beddington JR, Clark CW, Holt SJ, Laws RM (1979) Management of multispecies fisheries. Science 205:267-277

Mueter FJ, Megrey BA (2006) Using multi-species surplus production models to estimate ecosystem-level maximum sustainable yields. Fish Res 81:189-201

NEFSC (Northeast Fisheries Science Center) (2002) Final report of the working group on re-evaluation of biological reference points for New England groundfish. Reference Document 02-04. NEFSC, Woods Hole, MA

NEFSC (2007) Status of fishery resources off the northeastern United States. NEFSC, Woods Hole, MA

NEFSC (2008) Assessment of 19 northeast groundfish stocks through 2007: report of the 3rd groundfish assessment review meeting (GARM III), Northeast Fisheries Science Center, Woods Hole, Massachusetts, August 4-8, 2008. Section 2.1. Reference Document, 08-15. NEFSC, Woods Hole, MA

NMFS (National Marine Fisheries Service) (1999) Ecosystem-based fishery management. A report to Congress by the Ecosystems Principles Advisory Panel. US Department of Commerce, NOAA NMFS, Silver Spring, MD

> Nye JA, Link JS, Hare JA, Overholtz WJ (2009) Changing spatial distribution of fish stocks in relation to climate and population size on the Northeast United States continental shelf. Mar Ecol Prog Ser 393:111-129

O'Brien CM, Fox CJ, Planque B, Casey J (2000) Fisheries: climate variability and North Sea cod. Nature 404:142

Overholtz WJ, Link JS, Fogarty MJ, Col L, Legault C (2008) U.S. northeast shelf LME total fish biomass, target biological reference points for fish, and worldwide crosssystem comparisons. GARM Working Paper 3.1, NOAA NMFS, Woods Hole, MA

Pauly D, Christensen V (1995) Primary production required to sustain global fisheries. Nature 374:255-257

Pauly D, Christensen V, Dalsgaard J, Froese R, Torres F (1998) Fishing down marine food webs. Science 279: 860-863

Pauly D, Christensen V, Guenette S, Pitcher TJ and others (2002) Towards sustainability in world fisheries. Nature 418:689-695

Pikitch EK, Santora C, Babcock EA, Bakun A and others (2004) Ecosystem-based fishery management. Science 305:346-347

Pinnegar J, Blanchard J, Mackinson S, Scott R, Duplisea D (2005) Aggregation and removal of weak-links in foodweb models: system stability and recovery from disturbance. Ecol Model 184:229-248

Pitcher TJ, Hart PJB (1982) Fisheries ecology. Croom Helm, London

Plagányi ÉE (2007) Models for an ecosystem approach to fisheries. Fish Tech Pap 477. FAO, Rome

Platt T, Fuentes-Yaco T, Frank KT (2003) Spring algal bloom and larval fish survival. Nature 423:398-399
Pope JG (1975) The application of mixed fisheries theory to the cod and redfish stocks of subarea 2 and division $3 \mathrm{~K}$. ICNAF Research Document 75/IX/126. ICNAF, Dartmouth, NS

Pope J (1979) Stock assessment in multispecies fisheries, with special reference to the trawl fishery in the Gulf of Thailand. SCS/DEV/79/19. South China Sea Fisheries Development and Coordinating Program, Manila

Prager MH (1994) A suite of extensions to a nonequilibrium surplus-production model. Fish Bull (Seattle) 92:374-389

Quinn TJ II, Deriso RB (1999) Quantitative fishery dynamics. Oxford University Press, New York, NY

Rochet MJ, Collie JS, Jennings S, Hall SJ (2011) Does selective fishing conserve community biodiversity? Predictions from a length-based multispecies model. Can J Fish Aquat Sci 68:469-486

> Rose GA (2004) Reconciling overfishing and climate change with stock dynamics of Atlantic cod (Gadus morhua) over 500 years. Can J Fish Aquat Sci 61:1553-1557

> Ryther JH (1969) Photosynthesis and fish production in the sea. Science 166:72-76

Sainsbury KJ, Punt AE, Smith ADM (2000) Design of operational management strategies for achieving fishery ecosystem objectives. ICES J Mar Sci 57:731-741

Shin YJ, Shannon LJ, Bundy A, Coll M and others (2010a) Using indicators for evaluating, comparing and communicating the ecological status of exploited marine ecosystems. 2: Setting the scene. ICES J Mar Sci 67:692-716

Shin YJ, Bundy A, Shannon LJ, Simier M and others (2010b) Can simple be useful and reliable? Using ecological indicators for representing and comparing the states of marine ecosystems. ICES J Mar Sci 67:717-731

Sissenwine MP (1984) Why do fish populations vary? In: May RM (ed) Exploitation of marine communities. Springer-Verlag, New York, NY

Smith TD (1994) Scaling fisheries: the science of measuring the effects of fishing, 1855-1955. Cambridge University Press, New York, NY

Smith ADM, Sainsbury KJ, Stevens RA (1999) Implementing effective fisheries-management systems - management strategy evaluation and the Australian partnership approach. ICES J Mar Sci 56:967-979

> Spencer PD, Collie JS (1996) A simple predator-prey model of exploited marine fish populations incorporating alternative prey. ICES J Mar Sci 53:615-628

Townsend HM, Link JS, Osgood KE, Gedamke T and others (eds) (2008) Report of the NEMoW (National Ecosystem Modeling Workshop). NOAA Tech Memo NMFS-F/ SPO-87. NOAA, National Marine Fisheries Service, Silver Spring, MD

Tyrrell MC, Link JS, Moustahfid H (2011) The importance of including predation in fish population models: implications for biological reference points. Fish Res 108:1-8

Walters CJ (1986) Adaptive management of renewable resources. Macmillan Publishing Company, New York, NY

Walters CJ, Christensen V, Martell SJ, Kitchell JF (2005) Possible ecosystem impacts of applying MSY policies from single-species assessment. ICES J Mar Sci 62: 558-568

- Ware DM, Thomson RE (2005) Bottom-up ecosystem trophic dynamics determine fish production in the Northeast Pacific. Science 308:1280-1284

Worm B, Hilborn R, Baum JK, Branch TA and others (2009) Rebuilding global fisheries. Science 325:578-585 